\title{
Mathematical Model for Optimum Depth of Thermal Insulating Layer
}

\author{
Tanghong Lv \\ College of Science, Changchun University of Science and Technology \\ Changchun 130022, Jilin, China \\ E-mail: well2000@126.com
}

Received: March 10, 2011 Accepted: March 31, 2011 doi:10.5539/jmr.v3n3p103

\begin{abstract}
In order to ensure the comfort and health of buildings and resolve contradictory between improvement of thermal insulating function of buildings and reduce of thermosteresis and amount of basic building materials (namely save resourses), heat conduction equation was calculated. This mathematical physics equation which was calculated via finite difference method was attributed to inverse problem of gray distributed parameter systems. The economical model of optimum depth of thermal insulating layer was established. Finally, the optimum materials and depth was determined according to the two models.
\end{abstract}

Keywords: Heat conduction equation, Inverse problems of mathematical physics, Finite difference method, Economic optimization

\section{Background and analysis of the model}

Most of settlement housings in the city of China were flattop buildings, the highest surface temperature of which could reach $75^{\circ} \mathrm{C}$ in summer and the lowest surface temperature could reach $-40^{\circ} \mathrm{C}$ in winter. Many measures were carried out to keep suitable temperature inside buildings. On one hand, heating equipment and conditioner were setting up in buildings; on another hand, the thermal insulation ability of buildings was improving, so that the energy consumption would be decreased. The use of appropriate thermal insulation materials with appropriate depth was very important to ensure the comfort and health of buildings guarantee normal production and living, decrease energy consumption, reduce the weight of the roof system, reduce amount of basic building materials, which would save resources and reduce building costs.

\section{Hypothesis of the model}

1) A given thermal insulation material that transfer heat steadily.

2) The rooftop surfaced was considered flat, no significant changes of gradient.

3) The temperature distribution of rooftop flat surface was considered uniform, namely there was no temperature change within any flat surface. Only heat conduction at vertical direction was considered to affect temperature distribution.

4) The optimum depth of thermal insulation layer only related to type of thermal insulation materials, present value factor of life cycle, heating degree days, thermal resistance of non- thermal insulation layer and type of fuel for heating.

\section{Establishment and calculation of the model}

\subsection{Model 1: inversion model of thermal insulation layer depth of flattop buildings}

The structure of flat rooftop was showed in Figure 1.

1) Flattop buildings heat conduction equation

From model hypothesis, the heat conduction equation was:

$$
\lambda(z) \frac{\partial^{2} u}{\partial z^{2}}-\rho(z) c(z) \frac{\partial u}{\partial t}=0 \quad 0 \leq z \leq l \quad t>0
$$

$\lambda$ : Coefficient of heat conductivity of materials; $\rho$ : Dry density of material; $c$ : Specific heat of material; $u$ : Temperature of any site from flattop structure; $z$ : Spatial coordinate which is perpendicular with top flat; $l$ : Depth of flat top; $t$ : Time coordinate.

2) Initial conditions

The initial condition, which was the temperature distribution regularity of various layer of flat top at beginning of calculation, was given for No. 1 equation firstly. The time is 5:00 am. It is supposed that temperature distribution within flat top was uniform, so:

$$
\left.u\right|_{t=0}=\phi(z) \quad 0 \leq z \leq l
$$


$\phi(z)$ : Function of temperature change of various layers within flat top at beginning of calculation; the meanings of other symbols were same with above.

\section{3) Boundary conditions}

The outside surface of rooftop was calculated according to mixed boundary conditions. Namely, heat discharge of outside surface of rooftop is proportional with rooftop surface temperature and atmospheric temperature, so:

$$
-\left.\lambda_{0} \frac{\partial u}{\partial z}\right|_{z=0}=h_{0}\left(\left.u\right|_{z=0}-\theta_{\alpha}\right)
$$

$\lambda_{0}$ : Coefficient of heat conductivity of materials; $h_{0}$ : Coefficient of heat exchange between rooftop and medium around; $\alpha$ : Thermal radiation absorption coefficient of rooftop outside surface; $\theta_{\alpha}$ : Atmospheric temperature of outside rooftop; the meanings of other symbols were same with above.

Further consideration of sun radiation effect:

$$
\alpha I(t)-\left.\lambda_{0} \frac{\partial u}{\partial z}\right|_{z=0}=h_{0}\left(\left.u\right|_{z=0}-\theta_{\alpha}\right)
$$

$I(t)$ : Sun radiation intensity on surface of rooftop ; the meanings of other symbols were same with above.

The second boundary condition of inside surface of rooftop, namely

$$
\left.\frac{\partial u}{\partial z}\right|_{z=l}=\phi(t)
$$

4) Additional conditions

As it is about inverse problem of geometrical boundary of heat conduction equation, there were additional conditions in process of inversion calculation of thermal insulation layer depth.

$$
\left.u\right|_{z=l}=G(t) \quad t>0
$$

$G(t)$ : Function of temperature changes in various levels of inside rooftop at the moment of $t$.

5) Numerical methods

Finally, simulation of inside surface temperature of flat rooftop was made by finite difference method. Specific difference discrete format deduced from equation $(1) \sim(6)$ was as following:

$$
\left\{\begin{array}{l}
u_{i, j}=\frac{\tau}{h_{i}^{2} \rho_{i} c_{i}} \lambda_{i+1} u_{i+1, j}+\left(1-\frac{\tau}{h_{i}^{2} \rho_{i} c_{i}} \lambda_{i+1}-\frac{\tau}{h_{i}^{2} \rho_{i} c_{i}} \lambda_{i}\right) u_{i, j}+\frac{\tau}{h_{i}^{2} \rho_{i} c_{i}} \lambda_{i} u_{i-1, j} \\
u_{i, 0}=\phi(i h) \\
u_{0, j}=\varphi(j \tau) \\
u_{1, j}=\frac{h_{1} \alpha}{\lambda_{0}} I(j \tau)-\frac{h_{1} h_{0}-\lambda_{0}}{\lambda_{0}} u_{0, j}+\frac{h_{1} h_{0}}{\lambda_{0}} \theta_{\alpha} \\
u_{n+1, j}-u_{n, j}=\phi(j \tau)
\end{array}\right.
$$

$u_{i j}$ : Temperature of the $i$ layer of flat rooftop structure at the moment of $j ; \lambda_{i}$ : Coefficient of heat conductivity of the $i$ layer of materials; $h_{i}$ : Coefficient of heat exchange between the $i$ layer of materials and around medium; $\rho_{i}$ : Dry density of the $i$ layer of materials; $\tau$ : Time coordinate; the meanings of other symbols were same with above.

Here, $\mathrm{i}=0,1,2,3,4,5,6,7,8 ; \mathrm{j}=0,1,2,3 \ldots 26,27 ; \mathrm{n}=7 ; \tau=5$.

\subsection{Economical model of thermal insulation layer of flat rooftop}

Economical model of optimum depth of thermal insulation layer was established on the base of considering of thermal insulation materials type, present value factor of life cycle (PWF), heating degree days (HDD), thermal resistance of nonthermal insulation layer $\left(\mathrm{R}_{w t}\right)$ and type of fuel for heating.

1) Calculation of costs within life cycle of thermal insulation layer

The costs within life cycle of thermal insulation layer were composed of investment costs and fuel costs. The cost of thermal insulation materials per unit area was:

$$
C_{\text {in }}=C_{i} \times d
$$

$C_{i n}$ : Price of thermal insulation materials per unit area $\left(\right.$ Yuan $\left./ \mathrm{m}^{2}\right) ; C_{i}$ : Price of thermal insulation materials per unit volume $\left(\right.$ Yuan $\left./ \mathrm{m}^{3}\right) ; d$ : depth of thermal insulation materials. 
Heating fuel costs of outside wall per unit area every year were:

$$
C_{h}=\frac{86400 H D D \times C_{f}}{\left[\left(R_{w t}+d / \lambda_{m}\right) H \eta\right]}
$$

$C_{n}$ : Costs of heating fuel per unit area of rooftop $\left(\right.$ Yuan $\left./ m^{2} \cdot a\right)$.; $C_{f}$ : Price of heating fuel (Yuan $\left./ \mathrm{kg}\right) ; H D D$ : Heating degree days $\left({ }^{\circ} \cdot d\right) ; \lambda_{m}$ : Coefficient of heat conductivity of thermal insulation materials; $R_{w t}$ : Sum of thermal resistance of area inside and outside room and thermal resistance of other materials except thermal insulation layer; $H$ : calorific value of fuel $(\mathrm{kJ} / \mathrm{kg}) ; \eta$ : Efficiency of heating system.

The total costs of fuel used for heating in one unit of wall within the lifespan of thermal insulation layer were calculated by cycle value methods. As following:

$$
C_{t}=P W F \cdot C_{h}
$$

$C_{t}$ : The total costs of fuel used for heating in one unit of wall (Yuan $\left./ \mathrm{m}^{2}\right) ; P W F$ : Factor of life cycle.

The way of $P W F$ calculation was as following:

When $g>I$ :

$$
\left.I^{*}=£ I-g\right) /(1+g)
$$

When $g<I$ :

$$
I^{*}=(g-I) /(1+I)
$$

So:

$$
P W F=\left[1-\left(1+I^{*}\right)^{-N}\right] / I^{*}
$$

When $g=I$ :

$$
P W F=(1+I)^{-1}
$$

$I$ : Bank interest rate $(\%) ; g$ : The inflation rate $(\%) ; I *$ : The modified bank interest rate compared with the inflation rate $(\%) ; N$ : Years of life cycle of thermal insulation layer.

The annual heating costs of building were composed of investment costs of thermal insulation layer and fuel costs. So the total costs for every one unit of thermal insulation layer within life cycle were:

$$
C=\frac{86.4 \times P W F \times C_{f} \times H D D}{\left(R_{w t}+d / \lambda_{m}\right) H \eta}+C_{i} \times d
$$

Here, C: Total costs for every one unit of thermal insulation layer within life cycle $\left(Y u a n / m^{2}\right)$. the meanings of other symbols were same with above.

2) The equation for optimum depth of thermal insulation layer

Because $C=\frac{86.4 \times P W F \times C_{f} \times H D D}{\left(R_{w t}+d / \lambda_{m}\right) H \eta}+C_{i} \times d$, So the optimum depth of thermal insulation layer was descided as following:

$$
\frac{\partial C}{\partial d}=\frac{86.4 \times P W F \times C_{f} \times H D D}{H \eta h\left(R_{w t}+d / \lambda_{m}\right)^{2}}-C_{i}=0
$$

So the calculation equation of optimum depth of thermal insulation layer was:

$$
d_{o p}=\sqrt{\frac{86.4 \times C_{f} \times H D D \times m \times P W F}{H \eta C_{i}}}-m \times R_{w t}
$$




\section{Test and application of the model}

\subsection{Test of inversion model of thermal insulation layer depth of flattop buildings}

$u_{8 . j}$ was calculated by inversion model of thermal insulation layer depth. The equation set (7) was programmed by Matlab software. The detailed procedures were as following:

(1) The thermal insulation layer depth was estimated as [a,b] according to previous building experience.

(2) The temperature of inside surface was calculated by entering the two endpoint a and $b$. Then two curves of room temperature versus time were drawn up.

(3) Compare the above curves with the curves produced by actual measurement of temperatures at different time point in a day. If they were matched exactly, this range was the best for thermal insulation layer depth. If one endpoint did not satisfy the conditions, new endpoint could be got by split the above range via dichotomy. Then the new endpoint and another suitable endpoint form a new range $\left[a_{1}, b_{1}\right]$. Begin from ? and repeated.

Figure 2 showed the follow chart.

According to previous construct experience, the thermal insulation layer depth was estimated to be about $150 \mathrm{~mm} 400$ $\mathrm{mm}$ in this model, namely, $\mathrm{a}=150, \mathrm{~b}=400$. By inversion model, forward modeling and check of additional conditions, curves produced by program matched with actual curves when the thermal insulation layer depth was in the range of 180 $\mathrm{mm} \sim 300 \mathrm{~mm}$ (Figure 3).

From Figure 3, we can see that the depth of perlite thermal insulation layer was $180 \mathrm{~mm} 300 \mathrm{~mm}$ in summer. Similarly, when the depth of perlite thermal insulation layer was $200 \mathrm{~mm} 300 \mathrm{~mm}$ in winter, curves produced by program matched with actual curves (Figure 4).

From Figure 4, we can see that the depth of perlite thermal insulation layer was $200 \mathrm{~mm} 300 \mathrm{~mm}$ in winter. From above two cases, we can conclude that the optimum depth of thermal insulation layer was $200 \mathrm{~mm} 300 \mathrm{~mm}$.

\subsection{Test of economical model of thermal insulation layer of flat rooftop}

The latest four materials (Polyethylene foam, Styrofoam, Rigid Polyurethane foam and PVC rigid foam) were selected for determination of optimum materials as thermal insulation layer. The parameters of the four materials were listed in Table1.

Figure 5 showed relationship between depths of various thermal insulation layer materials and total costs of per unit area of thermal insulation layer within life cycle.

The depths of various materials with lowest total costs were showed in Figure 6.

The detailed data were listed in Table 2.

Analysis of PWF, HDD and $\mathrm{R}_{w t}$ were demonstrated in Figure 7 9.

From the figures, we can see that the depth of thermal insulation layer of Rigid Polyurethane foam and PVC rigid foam changed too much when Rwt, PWF and HDD changed. So they are not applicable. The suitable depth sof Polyethylene foam and Styrofoam acquired by inversion model were $(54,65)$ and $(43,55)$, respectively. The optimum depths of Polyethylene foam and Styrofoam acquired by economical model were $69.3649 \mathrm{~mm}, 52.8727 \mathrm{~mm}$, respectively. However, $69.3649 \mathrm{~mm}$ was not in the range $(54,65)$ in compare with $52.8727 \mathrm{~mm}$ was in the range $(43,55)$. Therefore, the optimum material was Styrofoam and its optimum depth was $52.8727 \mathrm{~mm}$.

\section{Evaluation of the model}

\subsection{Advantages of the model}

1) The models established in present study are easy to solve.

2) The knowledge used in this study is primary and the methods to solve problems are easy to understand.

3) Data processing and collecting correspond with national standard.

4) It was very scientific and applicable to consider both heat flow and economic in determination of the optimum thermal insulation layer materials.

\subsection{Disadvantages of the model}

1) Heat Conduction during various lays of rooftop was regarded as linear and unchanged in inversion model. However, this linear relationship did not exist in objective word, because the non-linear relationship such as, mutual restrict, saturation and limitation, could not be evitable.

2) The non-uniform distribution of various layers density of rooftop, thermal bridge existed in heat conduction during various layers and temperature fluctuation inside and outside the buildings will constrain the optimum depth determination. 
3) From Figure 7 9, we knew that the depth of thermal insulation layer correspond with PWF, HDD and $\mathrm{R}_{w t}$. However, the changes of PWF, HDD and $\mathrm{R}_{w t}$ were not be considered. This may cause deviation. So the model remained to be improved.

\section{References}

Huang, G.Y. \& Liu, X.J. (1993). Inverse problems in mathematical physics. Shandong Science and Technology Press. Shangdong. pp361-37.

JGJ26-95 standard of civil architecture energy-saving design: Heating and residential architecture. (1995). China Academy of Building Research. China Building Industry Press. Beijing.

Li, Y.F., Yang, Y.X., Gao, H. et al. (2004). Comparison and Economic and Technical Analysis of Some Heating Schemes in China. Building Energy and Environment, 23(4), 84-89.

Ma, J.Y. \& Xie, M. (1995). The analytical formula of multi-wall heat conduction and its application. Journal of Harbin University of Civil Engineering and Architecture, 28(6): 71-75.

Sun, C.R. (1998). Calculation and study of concrete, temperature field of Girder Bridge under the action of solar radiation heat. Acta of Harbin Architecture and Engineering College, 1, 92-101.

Zhao, H. \& Jin, H. (2001). Energy conservation multi-layer wall and heat insulating material. Journal of Harbin University of Civil Engineering and Architecture, 34(2), 83-85.

Zhu, Y.B. (2003). Application of thermal insulation materials in energy-saving walls. China Building Materials Industry Press. Beijing. pp14-87.

Appendix

Matlab source code:

1. The program to determine suitable thermal insulation layer depth in summer

r=input(' thermal insulation layer depth:');

$\mathrm{a}=\operatorname{zeros}(9,28) ; \mathrm{b}=\operatorname{zeros}(1,27)$;

$\mathrm{p}=\left[\begin{array}{llllll}600 & 180025018002400 & 1800 & 370\end{array}\right]$;\%density

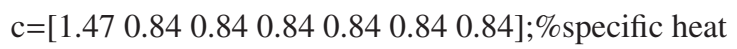

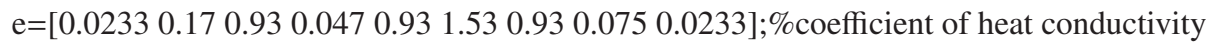

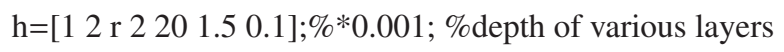

$\mathrm{i}=\left[\begin{array}{l}122.4 \\ 162.3 \\ 203.7\end{array} 324.2392 .6467 .8504 .0624 .6630 .0640 .6691 .5691 .51717 .8732 .9723 .4713 .4708 .0682 .2663 .9\right.$

$569.4418 .4381 .1320 .0294 .9231 .3125 .7121 .0119 .2]$; \%intensity of sun radiation

$\mathrm{e} 0=0.0233$; \%coefficient of heat conductivity of air

$\mathrm{f}=0.74 ; \%$ absorption coefficient of rooftop

h0 $=39.808$; \%coefficient of heat exchange of rooftop

for $n=1: 9$

if $n==1$

$\mathrm{a}(\mathrm{n}, 1)=22.4$;

elseif $n==2$

$\mathrm{a}(\mathrm{n}, 1)=-4.4 * \operatorname{sum}(\mathrm{n}-1) /(2 * \operatorname{sum}(7))+22.4$;

elseif $\mathrm{n}==9$

$\mathrm{a}(\mathrm{n}, 1)=18$;

else

$\operatorname{sum}=\operatorname{cumsum}(\mathrm{h})$;

$\mathrm{a}(\mathrm{n}, 1)=-4.4 *(\operatorname{sum}(\mathrm{n}-1)+\operatorname{sum}(\mathrm{n}-2)) /(2 * \operatorname{sum}(7))+22.4$;

end

end 
temperature outdoor

for $\mathrm{j}=2: 28$

$\mathrm{a}(2, \mathrm{j})=(\mathrm{h}(1) * 0.01 * \mathrm{i}(\mathrm{j}) * 4.18 * 1000 / 3600 * \mathrm{f} / \mathrm{e} 0+(\mathrm{h}(1) * 0.01 * 23-\mathrm{e} 0) / \mathrm{e} 0 * \mathrm{a}(1, \mathrm{j})+\mathrm{h}(1) * 0.01 * 23 * 25 / \mathrm{e} 0) * 0.085-0.15 *(0.5 * \mathrm{j}-12) 2$;

end

for $\mathrm{j}=2: 28$

if $r_{i} 29 \& r_{i} 23$

if $\mathrm{j}_{i} 19$

for $m=3: 8$

$\mathrm{a}(\mathrm{m}, \mathrm{j})=0.5 * 3.6 /(\mathrm{h}(\mathrm{m}-1) 2 * \mathrm{p}(\mathrm{m}-1) * \mathrm{c}(\mathrm{m}-1)) * \mathrm{e}(\mathrm{m}) * \mathrm{a}(\mathrm{m}+1, \mathrm{j}-1)+(1-0.5 * 3.6 /(\mathrm{h}(\mathrm{m}-1) 2 * \mathrm{p}(\mathrm{m}-1) * \mathrm{c}(\mathrm{m}-1)) * \mathrm{e}(\mathrm{m})-0.5 * 3.6 /(\mathrm{h}(\mathrm{m}-$ 1) $2 * \mathrm{p}(\mathrm{m}-1) * \mathrm{c}(\mathrm{m}-1)) * \mathrm{e}(\mathrm{m}-1)) * \mathrm{a}(\mathrm{m}, \mathrm{j}-1)+0.5 * 3.6 /(\mathrm{h}(\mathrm{m}-1) 2 * \mathrm{p}(\mathrm{m}-1) * \mathrm{c}(\mathrm{m}-1)) * \mathrm{e}(\mathrm{m}-1) * \mathrm{a}(\mathrm{m}-1, \mathrm{j}-1)+0.45 * \sin (30 * \mathrm{j})+0.0041 *(\mathrm{r}-$ 30) $2+0.02$;

$\mathrm{b}(\mathrm{j}-1)=-1 *(1+\mathrm{j})(-3.5) *(0.5 * \mathrm{j}-10) 2+2.221$;

end

else

for $m=3: 8$

$\mathrm{a}(\mathrm{m}, \mathrm{j})=0.5 * 3.6 /(\mathrm{h}(\mathrm{m}-1) 2 * \mathrm{p}(\mathrm{m}-1) * \mathrm{c}(\mathrm{m}-1)) * \mathrm{e}(\mathrm{m}) * \mathrm{a}(\mathrm{m}+1, \mathrm{j}-1)+(1-0.5 * 3.6 /(\mathrm{h}(\mathrm{m}-1) 2 * \mathrm{p}(\mathrm{m}-1) * \mathrm{c}(\mathrm{m}-1)) * \mathrm{e}(\mathrm{m})-0.5 * 3.6 /(\mathrm{h}(\mathrm{m}-$ 1) $2 * \mathrm{p}(\mathrm{m}-1) * \mathrm{c}(\mathrm{m}-1)) * \mathrm{e}(\mathrm{m}-1)) * \mathrm{a}(\mathrm{m}, \mathrm{j}-1)+0.5 * 3.6 /(\mathrm{h}(\mathrm{m}-1) 2 * \mathrm{p}(\mathrm{m}-1) * \mathrm{c}(\mathrm{m}-1)) * \mathrm{e}(\mathrm{m}-1) * \mathrm{a}(\mathrm{m}-1, \mathrm{j}-1)+0.45 * \sin (30 * \mathrm{j})+0.0041 *(\mathrm{r}-$ 30) 2-0.29;

$\mathrm{b}(\mathrm{j}-1)=-1 *(1+\mathrm{j})(-3.5) *(0.5 * \mathrm{j}-10) 2+2.221$;

end

end

else

if $\mathrm{j}_{i} 19$

for $m=3: 8$

$\mathrm{a}(\mathrm{m}, \mathrm{j})=0.5 * 3.6 /(\mathrm{h}(\mathrm{m}-1) 2 * \mathrm{p}(\mathrm{m}-1) * \mathrm{c}(\mathrm{m}-1)) * \mathrm{e}(\mathrm{m}) * \mathrm{a}(\mathrm{m}+1, \mathrm{j}-1)+(1-0.5 * 3.6 /(\mathrm{h}(\mathrm{m}-1) 2 * \mathrm{p}(\mathrm{m}-1) * \mathrm{c}(\mathrm{m}-1)) * \mathrm{e}(\mathrm{m})-0.5 * 3.6 /(\mathrm{h}(\mathrm{m}-$ 1) $2 * \mathrm{p}(\mathrm{m}-1) * \mathrm{c}(\mathrm{m}-1)) * \mathrm{e}(\mathrm{m}-1)) * \mathrm{a}(\mathrm{m}, \mathrm{j}-1)+0.5 * 3.6 /(\mathrm{h}(\mathrm{m}-1) 2 * \mathrm{p}(\mathrm{m}-1) * \mathrm{c}(\mathrm{m}-1)) * \mathrm{e}(\mathrm{m}-1) * \mathrm{a}(\mathrm{m}-1, \mathrm{j}-1)+0.45 * \sin (\mathrm{r} * \mathrm{j})+0.0041 *(\mathrm{r}-$ 25) $2+0.029$;

$\mathrm{b}(\mathrm{j}-1)=-1 *(1+\mathrm{j})(-3.5) *(0.5 * \mathrm{j}-10) 2+2.221$;

end

else

for $m=3: 8$

$\mathrm{a}(\mathrm{m}, \mathrm{j})=0.5 * 3.6 /(\mathrm{h}(\mathrm{m}-1) 2 * \mathrm{p}(\mathrm{m}-1) * \mathrm{c}(\mathrm{m}-1)) * \mathrm{e}(\mathrm{m}) * \mathrm{a}(\mathrm{m}+1, \mathrm{j}-1)+(1-0.5 * 3.6 /(\mathrm{h}(\mathrm{m}-1) 2 * \mathrm{p}(\mathrm{m}-1) * \mathrm{c}(\mathrm{m}-1)) * \mathrm{e}(\mathrm{m})-0.5 * 3.6 /(\mathrm{h}(\mathrm{m}-$ 1) $2 * \mathrm{p}(\mathrm{m}-1) * \mathrm{c}(\mathrm{m}-1)) * \mathrm{e}(\mathrm{m}-1)) * \mathrm{a}(\mathrm{m}, \mathrm{j}-1)+0.5 * 3.6 /(\mathrm{h}(\mathrm{m}-1) 2 * \mathrm{p}(\mathrm{m}-1) * \mathrm{c}(\mathrm{m}-1)) * \mathrm{e}(\mathrm{m}-1) * \mathrm{a}(\mathrm{m}-1, \mathrm{j}-1)+0.45 * \sin (\mathrm{r} * \mathrm{j})+0.0041 *(\mathrm{r}-$ 25) 2-0.29;

$b(j-1)=-1 *(1+j)(-3.5) *(0.5 * j-10) 2+2.221$;

end

end

end

end

for $\mathrm{j}=2: 28$

$a(9, j)=a(8, j)+b(j-1)$;

end

a

$\mathrm{x}=$ linspace $(5,18.5,28)$; 
$\mathrm{y}=\mathrm{a}(9,1: 28)$;

$\mathrm{s}=\operatorname{subplot}(1,1,1)$;

$\mathrm{z}=$ linspace $(5,19,15)$;

plot(x,y,'o-');

set(s,'XTick',z);

When the depth of thermal insulation layer $\mathrm{r}=25$, the program running results were showed in Table 1.

Table 1

\begin{tabular}{|l|l|l|l|l|l|l|}
\hline 22.4 & 23.5 & 23 & 23 & 23.6 & 23.8 & 25 \\
\hline 22.08571 & 25.634 & 28.16716 & 33.48173 & 37.54067 & 41.43612 & 44.78818 \\
\hline 22.22946 & 22.21447 & 22.73912 & 23.12285 & 22.92386 & 22.68626 & 23.01987 \\
\hline 21.07829 & 21.06364 & 21.58846 & 21.97225 & 21.77306 & 21.53506 & 21.86805 \\
\hline 19.92713 & 19.91222 & 20.43678 & 20.82031 & 20.62087 & 20.38261 & 20.71534 \\
\hline 18.98915 & 18.97448 & 19.49928 & 19.88305 & 19.68386 & 19.44584 & 19.77881 \\
\hline 18.07248 & 18.05852 & 18.58405 & 18.96817 & 18.76916 & 18.53124 & 18.86428 \\
\hline 18.00426 & 18.02616 & 17.7854 & 17.8268 & 17.46803 & 17.17206 & 17.49121 \\
\hline 18 & 18.51511 & 19.44195 & 19.81883 & 19.58272 & 19.33907 & 19.68304 \\
\hline
\end{tabular}

2. Determine suitable thermal insulation layer depth in winter

$\mathrm{r}=$ input(' thermal insulation layer depth:');

$\mathrm{a}=\operatorname{zeros}(9,28) ; \mathrm{b}=\operatorname{zeros}(1,27)$;

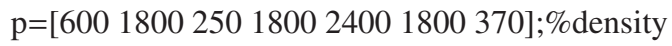

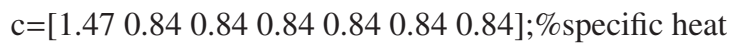

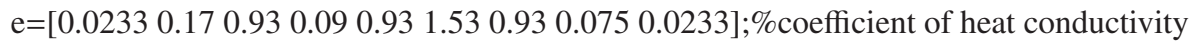

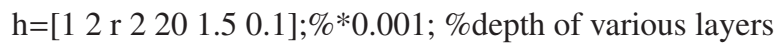

$\mathrm{i}=\left[\begin{array}{l}122.4162 .3203 .7324 .2392 .6467 .8504 .0624 .6630 .0640 .6691 .5691 .51717 .8732 .9723 .4713 .4708 .0682 .2663 .9\end{array}\right.$

$569.4418 .4381 .1320 .0294 .9231 .3125 .7121 .0119 .2]$; \%intensity of sun radiation

$\mathrm{e} 0=0.0233$; \%coefficient of heat conductivity of air

$\mathrm{f}=0.74 ; \%$ absorption coefficient of rooftop

$\mathrm{h} 0=39.808$; \%coefficient of heat exchange of rooftop

for $\mathrm{n}=1: 9$

if $n==1$

$\mathrm{a}(\mathrm{n}, 1)=-17$;

elseif $\mathrm{n}==2$

$\mathrm{a}(\mathrm{n}, 1)=33 * \operatorname{sum}(\mathrm{n}-1) /(2 * \operatorname{sum}(7))-17$;

elseif $\mathrm{n}==9$

$\mathrm{a}(\mathrm{n}, 1)=16$;

else

$\operatorname{sum}=\operatorname{cumsum}(\mathrm{h})$;

$\mathrm{a}(\mathrm{n}, 1)=33 *(\operatorname{sum}(\mathrm{n}-1)+\operatorname{sum}(\mathrm{n}-2)) /(2 * \operatorname{sum}(7))-17$;

end

end

$\mathrm{a}(1,2: 28)=[-17.45-17.3-17.4-17-15.38-14.5-14-14-13.5-13.5-13-13-11.5-9-7-6-4.5-4.5-5-6$ - -5 - -7 - -9 - $-9.5-10$

$-11-13] ; \%$ Suitable outdoor temperature

for $\mathrm{j}=2: 28$

$\mathrm{a}(2, \mathrm{j})=(\mathrm{h}(1) * 0.01 * \mathrm{i}(\mathrm{j}) / 60 * 4.18 * 1000 / 3600 * \mathrm{f} / \mathrm{e} 0+(\mathrm{h}(1) * 0.01 * 23-\mathrm{e} 0) / \mathrm{e} 0 * \mathrm{a}(1, \mathrm{j})+\mathrm{h}(1) * 0.01 * 23 * 25 / \mathrm{e} 0) * 0.085-0.15 *(0.5 * \mathrm{j}-12)$ 
2-30;

end

for $\mathrm{j}=2: 28$

if $r_{i} 29 \& r_{i} 23$

if $\mathrm{j}_{i} 19$

for $\mathrm{m}=3: 8$

$\mathrm{a}(\mathrm{m}, \mathrm{j})=0.5 * 3.6 /(\mathrm{h}(\mathrm{m}-1) 2 * \mathrm{p}(\mathrm{m}-1) * \mathrm{c}(\mathrm{m}-1)) * \mathrm{e}(\mathrm{m}) * \mathrm{a}(\mathrm{m}+1, \mathrm{j}-1)+(1-0.5 * 3.6 /(\mathrm{h}(\mathrm{m}-1) 2 * \mathrm{p}(\mathrm{m}-1) * \mathrm{c}(\mathrm{m}-1)) * \mathrm{e}(\mathrm{m})-0.5 * 3.6 /(\mathrm{h}(\mathrm{m}-$ 1) $2 * \mathrm{p}(\mathrm{m}-1) * \mathrm{c}(\mathrm{m}-1)) * \mathrm{e}(\mathrm{m}-1)) * \mathrm{a}(\mathrm{m}, \mathrm{j}-1)+0.5 * 3.6 /(\mathrm{h}(\mathrm{m}-1) 2 * \mathrm{p}(\mathrm{m}-1) * \mathrm{c}(\mathrm{m}-1)) * \mathrm{e}(\mathrm{m}-1) * \mathrm{a}(\mathrm{m}-1, \mathrm{j}-1)+0.45 * \sin (30 * \mathrm{j})+0.0041 *(\mathrm{r}-$ 30) $2+0.02$;

$\mathrm{b}(\mathrm{j}-1)=-1 *(1+\mathrm{j})(-3.5) *(0.5 * \mathrm{j}-10) 2+2.221$;

end

else

for $m=3: 8$

$\mathrm{a}(\mathrm{m}, \mathrm{j})=0.5 * 3.6 /(\mathrm{h}(\mathrm{m}-1) 2 * \mathrm{p}(\mathrm{m}-1) * \mathrm{c}(\mathrm{m}-1)) * \mathrm{e}(\mathrm{m}) * \mathrm{a}(\mathrm{m}+1, \mathrm{j}-1)+(1-0.5 * 3.6 /(\mathrm{h}(\mathrm{m}-1) 2 * \mathrm{p}(\mathrm{m}-1) * \mathrm{c}(\mathrm{m}-1)) * \mathrm{e}(\mathrm{m})-0.5 * 3.6 /(\mathrm{h}(\mathrm{m}-$ 1) $2 * \mathrm{p}(\mathrm{m}-1) * \mathrm{c}(\mathrm{m}-1)) * \mathrm{e}(\mathrm{m}-1)) * \mathrm{a}(\mathrm{m}, \mathrm{j}-1)+0.5 * 3.6 /(\mathrm{h}(\mathrm{m}-1) 2 * \mathrm{p}(\mathrm{m}-1) * \mathrm{c}(\mathrm{m}-1)) * \mathrm{e}(\mathrm{m}-1) * \mathrm{a}(\mathrm{m}-1, \mathrm{j}-1)+0.45 * \sin (30 * \mathrm{j})+0.0041 *(\mathrm{r}-$ 30) $2-0.29$;

$\mathrm{b}(\mathrm{j}-1)=-1 *(1+\mathrm{j})(-3.5) *(0.5 * \mathrm{j}-10) 2+2.221$;

end

end

else

if $\mathrm{j}_{i} 19$

for $m=3: 8$

$\mathrm{a}(\mathrm{m}, \mathrm{j})=0.5 * 3.6 /(\mathrm{h}(\mathrm{m}-1) 2 * \mathrm{p}(\mathrm{m}-1) * \mathrm{c}(\mathrm{m}-1)) * \mathrm{e}(\mathrm{m}) * \mathrm{a}(\mathrm{m}+1, \mathrm{j}-1)+(1-0.5 * 3.6 /(\mathrm{h}(\mathrm{m}-1) 2 * \mathrm{p}(\mathrm{m}-1) * \mathrm{c}(\mathrm{m}-1)) * \mathrm{e}(\mathrm{m})-0.5 * 3.6 /(\mathrm{h}(\mathrm{m}-$ 1) $2 * \mathrm{p}(\mathrm{m}-1) * \mathrm{c}(\mathrm{m}-1)) * \mathrm{e}(\mathrm{m}-1)) * \mathrm{a}(\mathrm{m}, \mathrm{j}-1)+0.5 * 3.6 /(\mathrm{h}(\mathrm{m}-1) 2 * \mathrm{p}(\mathrm{m}-1) * \mathrm{c}(\mathrm{m}-1)) * \mathrm{e}(\mathrm{m}-1) * \mathrm{a}(\mathrm{m}-1, \mathrm{j}-1)+0.45 * \sin (\mathrm{r} * \mathrm{j})+0.0041 *(\mathrm{r}-$ 25) $2+0.029$;

$\mathrm{b}(\mathrm{j}-1)=-1 *(1+\mathrm{j})(-3.5) *(0.5 * \mathrm{j}-10) 2+2.221$;

end

else

for $\mathrm{m}=3: 8$

$\mathrm{a}(\mathrm{m}, \mathrm{j})=0.5 * 3.6 /(\mathrm{h}(\mathrm{m}-1) 2 * \mathrm{p}(\mathrm{m}-1) * \mathrm{c}(\mathrm{m}-1)) * \mathrm{e}(\mathrm{m}) * \mathrm{a}(\mathrm{m}+1, \mathrm{j}-1)+(1-0.5 * 3.6 /(\mathrm{h}(\mathrm{m}-1) 2 * \mathrm{p}(\mathrm{m}-1) * \mathrm{c}(\mathrm{m}-1)) * \mathrm{e}(\mathrm{m})-0.5 * 3.6 /(\mathrm{h}(\mathrm{m}-$ 1) $2 * \mathrm{p}(\mathrm{m}-1) * \mathrm{c}(\mathrm{m}-1)) * \mathrm{e}(\mathrm{m}-1)) * \mathrm{a}(\mathrm{m}, \mathrm{j}-1)+0.5 * 3.6 /(\mathrm{h}(\mathrm{m}-1) 2 * \mathrm{p}(\mathrm{m}-1) * \mathrm{c}(\mathrm{m}-1)) * \mathrm{e}(\mathrm{m}-1) * \mathrm{a}(\mathrm{m}-1, \mathrm{j}-1)+0.45 * \sin (\mathrm{r} * \mathrm{j})+0.0041 *(\mathrm{r}-$ 25) $2-0.29$;

$\mathrm{b}(\mathrm{j}-1)=-1 *(1+\mathrm{j})(-3.5) *(0.5 * \mathrm{j}-10) 2+2.221$;

end

end

end

end

for $\mathrm{j}=2: 28$

$a(9, j)=a(8, j)+b(j-1)$;

end

a

$\mathrm{x}=$ linspace $(5,18.5,28)$;

$\mathrm{y}=\mathrm{a}(9,1: 28)$;

$\mathrm{s}=\operatorname{subplot}(1,1,1)$; 
$\mathrm{Z}=$ linspace $(5,19,15)$;

$\operatorname{plot}\left(\mathrm{x}, \mathrm{y}, \mathrm{o-}^{\prime}\right)$;

set(s,'XTick', z);

3. Optimization of the model for calculation of thermal insulation layer depth

HDD $=4471 ; \%$ HDD

$\mathrm{Cf}=0.150 ; \%$ price of fuel

$\mathrm{H}=21000$; $\%$ calorific value

$\mathrm{h}=0.75 ; \%$ coefficient of heat supply efficiency

$\mathrm{Ci}=\left[\begin{array}{lll}210 & 300230320\end{array}\right]$ \% price of materials

$\mathrm{m}=\left[\begin{array}{llll}0.047 & 0.042 & 0.33 & 0.48\end{array}\right]$; coefficient of heat conductivity

$\mathrm{Rwt}=0.4119 ; \%$ sum of heat resistance except thermal insulation layer

$\mathrm{g}=0.05 ; \%$ rate of inflation

$\mathrm{I}=0.0414 ; \%$ bank rate

$\mathrm{Iw}=(\mathrm{g}-\mathrm{I}) /(1+\mathrm{I}) ; \%$ modified bank rate compared with inflation rate $\mathrm{PWF}=(1-(1+\mathrm{Iw})(-10)) / \mathrm{Iw} ; \% \mathrm{PWF}$

$\mathrm{C}=$ zeros $(4,16) ; \%$ total costs of a unit area thermal insulation layer within life cycle

dop=zeros $(1,4) ; \%$ the optimum depth

$\mathrm{C} 1=$ zeros $(1,4) ; \%$ the optimum costs of a unit area thermal insulation layer

$\mathrm{d}=$ linspace $(0,150,16)$;

for $\mathrm{a}=1: 4$

for $b=1: 16$

$\mathrm{C}(\mathrm{a}, \mathrm{b})=86.4 * \mathrm{PWF} * \mathrm{Cf} * \mathrm{HDD} /\left((\mathrm{Rwt}+\mathrm{d}(\mathrm{b}) * 0.001 / \mathrm{m}(\mathrm{a}))^{*} \mathrm{H} * \mathrm{~h}\right)+\mathrm{Ci}(\mathrm{a}) * \mathrm{~d}(\mathrm{~b}) * 0.001$;

end

$\operatorname{dop}(a)=\left(\left(86.400 * \mathrm{Cf}^{*} \mathrm{HDD}^{*} \mathrm{~m}(\mathrm{a}) * \mathrm{PWF} /(\mathrm{H} * \mathrm{~h} * \mathrm{Ci}(\mathrm{a}))\right)(1 / 2)-\mathrm{m}(\mathrm{a}) * \mathrm{Rwt}\right) * 1000 ;$

end

C

dop

for $b=1: 4$

$\mathrm{C} 1(\mathrm{~b})=86.4 * \mathrm{PWF} * \mathrm{Cf} * \mathrm{HDD} /\left((\mathrm{Rwt}+\mathrm{dop}(\mathrm{b}) * 0.001 / \mathrm{m}(\mathrm{b})) * \mathrm{H}^{*} \mathrm{~h}\right)+\mathrm{Ci}(\mathrm{b}) * \mathrm{dop}(\mathrm{b}) * 0.001$;

end

C1

$\mathrm{x}=$ linspace $(0,150,16)$;

$\mathrm{y}=\mathrm{C}(1,:)$;

$\mathrm{z}=$ linspace $(30,100,15)$;

$\mathrm{s}=\operatorname{subplot}(1,1,1)$;

plot(x,y,'*-g','lineWidth',2);

\%legend('costs of Polyethylene foam',1);

hold on;

$\mathrm{y}=\mathrm{C}(2,:)$;

plot(x,y,'square-m','lineWidth',2);

\%legend('costs of Styrofoam',1);

hold on;

$\mathrm{y}=\mathrm{C}(3,:)$; 
plot(x,y,' -r','lineWidth',2);

$\%$ legend('costs of Rigid Polyurethane foam',1);

hold on;

$\mathrm{y}=\mathrm{C}(4,:)$;

plot(x,y,'pentagram-b','lineWidth',2);

\%legend('costs of PVC rigid foam',1);

xlabel('depth of thermal insulation layer(mm)');

ylabel('Costs(Yuan/m 2)');

$\operatorname{set}\left(\mathrm{s},{ }^{\prime}\right.$ XTick',x);

set(s,'YTick',z);

grid;

The running results were showed in Table 2.

4. Optimization of models to get optimum depth and lowest costs

$\mathrm{HDD}=4471 ; \% \mathrm{HDD}$

$\mathrm{Cf}=0.150 ; \%$ price of fuel

$\mathrm{H}=21000 ; \%$ calorific value

$\mathrm{h}=0.75 ; \%$ coefficient of heat supply efficiency

$\mathrm{Ci}=\left[\begin{array}{ll}210 & 300230320\end{array}\right]$;\%price of materials

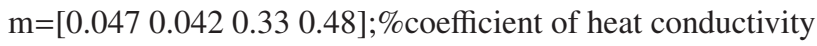

$\mathrm{Rwt}=0.4119 ; \%$ sums of heat resistance except thermal insulation layer

$\mathrm{g}=0.05 ; \%$ rate of inflation

$\mathrm{I}=0.0414 ; \%$ bank rate

$\mathrm{Iw}=(\mathrm{g}-\mathrm{I}) /(1+\mathrm{I}) ; \%$ modified bank rate compared with inflation rate

$\mathrm{PWF}=(1-(1+\mathrm{Iw})(-10)) / \mathrm{Iw} ; \% \mathrm{PWF}$

$\mathrm{C}=$ zeros $(4,16) ; \%$ total costs of a unit area thermal insulation layer within life cycle

dop=zeros $(1,4) ; \%$ the optimum depth

$\mathrm{C} 1=$ zeros $(1,4) ; \%$ the optimum costs of a unit area thermal insulation layer

$\mathrm{d}=$ linspace $(0,150,16)$;

for $\mathrm{a}=1: 4$

for $b=1: 16$

$\mathrm{C}(\mathrm{a}, \mathrm{b})=86.4 * \mathrm{PWF}^{*} \mathrm{Cf} * \mathrm{HDD} /\left((\mathrm{Rwt}+\mathrm{d}(\mathrm{b}) * 0.001 / \mathrm{m}(\mathrm{a}))^{*} \mathrm{H}^{*} \mathrm{~h}\right)+\mathrm{Ci}(\mathrm{a}) * \mathrm{~d}(\mathrm{~b}) * 0.001$;

end

$\operatorname{dop}(\mathrm{a})=\left(\left(86.400 * \mathrm{Cf} * \mathrm{HDD} * \mathrm{~m}(\mathrm{a}) * \mathrm{PWF} /\left(\mathrm{H}^{*} \mathrm{~h}^{*} \mathrm{Ci}(\mathrm{a})\right)\right)(1 / 2)-\mathrm{m}(\mathrm{a}) * \mathrm{Rwt}\right) * 1000 ;$

end

dop

C

for $b=1: 4$

C1(b) $=86.4 * \mathrm{PWF}^{*} \mathrm{Cf} * \mathrm{HDD} /\left((\mathrm{Rwt}+\operatorname{dop}(\mathrm{b}) * 0.001 / \mathrm{m}(\mathrm{b}))^{*} \mathrm{H}^{*} \mathrm{~h}\right)+\mathrm{Ci}(\mathrm{b}) * \operatorname{dop}(\mathrm{b}) * 0.001$;

end

C1

$\mathrm{x}=$ linspace $(0,150,16)$;

$\mathrm{y}=\mathrm{C}(1,:)$; 
$\mathrm{z}=$ linspace $(30,100,15)$;

$\mathrm{s}=\operatorname{subplot}(1,1,1)$;

plot(x,y,'*-g', 'lineWidth',2);

\%legend('costs of Polyethylene foam',1);

hold on;

$\mathrm{y}=\mathrm{C}(2,:)$;

plot(x,y,'square-m','lineWidth',2);

\%legend('costs of Styrofoam',1);

hold on;

$\mathrm{y}=\mathrm{C}(3,:)$;

plot(x,y,' -r','lineWidth',2);

\%legend('costs of Rigid Polyurethane foam',1);

hold on;

$\mathrm{y}=\mathrm{C}(4,:)$;

plot(x,y,'pentagram-b','lineWidth', 2);

\%legend('costs of PVC rigid foam',1);

xlabel('depth of thermal insulation layer(mm)');

ylabel('total costs(Yuan/m 2)');

set(s,'XTick',[dop(4),dop(2),dop(1),dop(3)]);

set(s,'YTick',[C1(1),C1(2),C1(3),C1(4)]);

grid; 
Table 1. The parameters of four latest materials

\begin{tabular}{|l|l|l|}
\hline Material of thermal insulation layer & $\begin{array}{l}\text { Coefficient of heat conductivity } \\
(W /(m \cdot K))\end{array}$ & Price $\left({\left.\text { Yuan } / \mathrm{m}^{3}\right)}^{3}\right.$ \\
\hline Polyethylene foam & 0.047 & 210 \\
\hline Styrofoam & 0.042 & 300 \\
\hline Rigid Polyurethane foam & 0.033 & 230 \\
\hline PVC rigid foam & 0.048 & 320 \\
\hline
\end{tabular}

Table 2. The corresponding depth of thermal insulation layer with the lowest costs

\begin{tabular}{|l|l|l|}
\hline $\begin{array}{l}\text { Materials of thermal insulation } \\
\text { layer }\end{array}$ & $\begin{array}{l}\text { Lowest } \\
\text { (Yuan/m2) }\end{array}$ & $\begin{array}{l}\text { The corresponding depth of thermal } \\
\text { insulation layer }(\mathrm{mm})\end{array}$ \\
\hline Polyethylene foam & 33.1987 & 69.3649 \\
\hline Styrofoam & 36.9136 & 52.8727 \\
\hline Rigid Polyurethane foam & 72.0733 & 88.7176 \\
\hline PVC rigid foam & 83.7359 & 31.9814 \\
\hline
\end{tabular}

Table 3. Intensity of sun radiation at different moments

\begin{tabular}{cc||cc||cc}
\hline Time & Sun radiation $\mathrm{kcal} /\left(\mathrm{m}^{2} \cdot \mathrm{h}\right)$ & Time & Sun radiation $\mathrm{kcal} /\left(\mathrm{m}^{2} \cdot \mathrm{h}\right)$ & Time & Sun radiation $\mathrm{kcal} /\left(\mathrm{m}^{2} \cdot \mathrm{h}\right)$ \\
\hline $5: 00$ & 122.4 & $10: 00$ & 691.5 & $15: 00$ & 418.4 \\
$5: 30$ & 162.3 & $10: 30$ & 691.51 & $15: 30$ & 381.1 \\
$6: 00$ & 203.7 & $11: 00$ & 717.8 & $16: 00$ & 320.0 \\
$6: 30$ & 324.2 & $11: 30$ & 732.9 & $16: 30$ & 294.9 \\
$7: 00$ & 392.6 & $12: 00$ & 723.4 & $17: 00$ & 231.3 \\
$7: 30$ & 467.8 & $12: 30$ & 713.4 & $17: 30$ & 125.7 \\
$8: 00$ & 504.0 & $13: 00$ & 708.0 & $18: 00$ & 121.0 \\
$8: 30$ & 624.6 & $13: 30$ & 682.2 & $18: 30$ & 119.2 \\
$9: 00$ & 630.0 & $14: 00$ & 663.9 & & \\
$9: 30$ & 640.6 & $14: 30$ & 569.4 & & \\
\hline
\end{tabular}

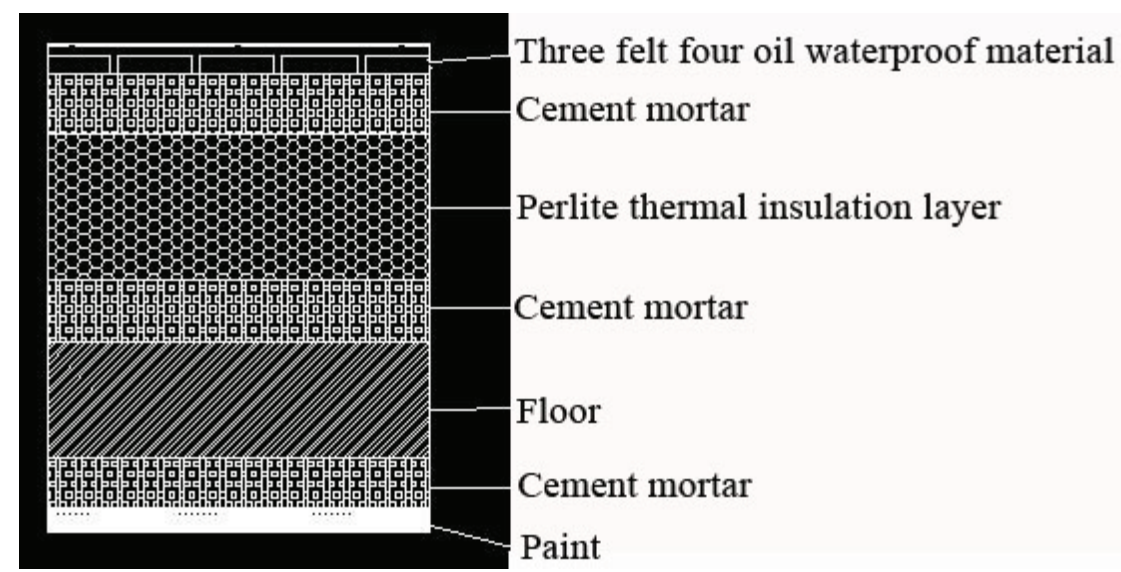

Figure 1. Structure of flat rooftop 


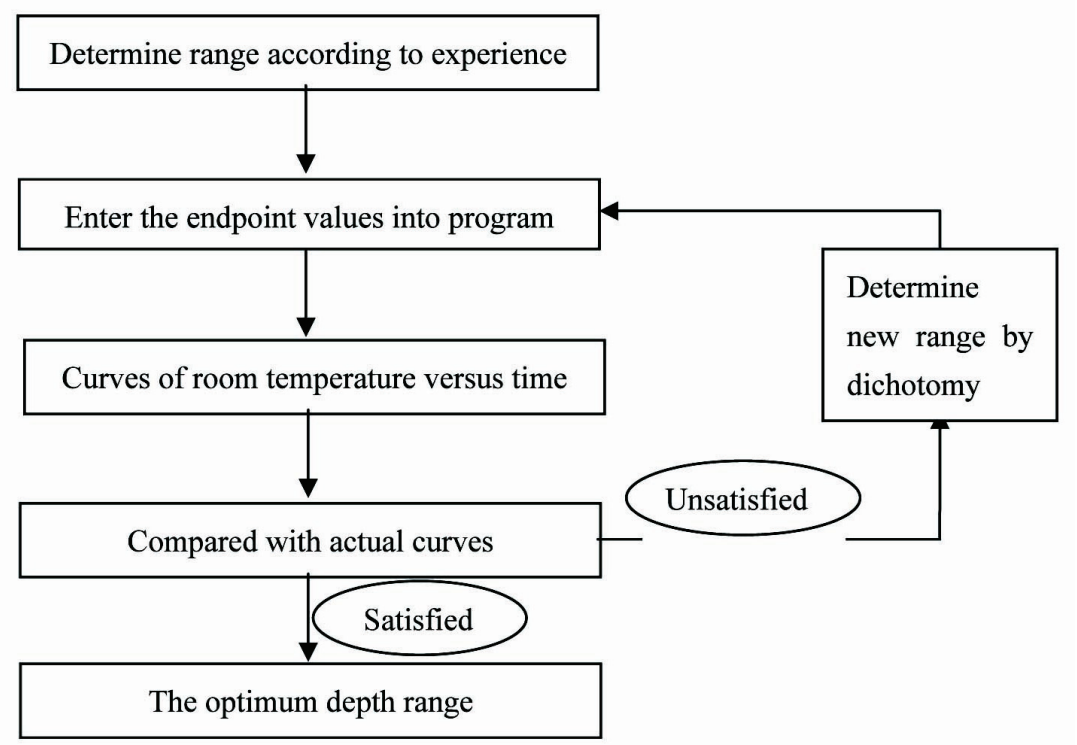

Figure 2. Follow chart of solver

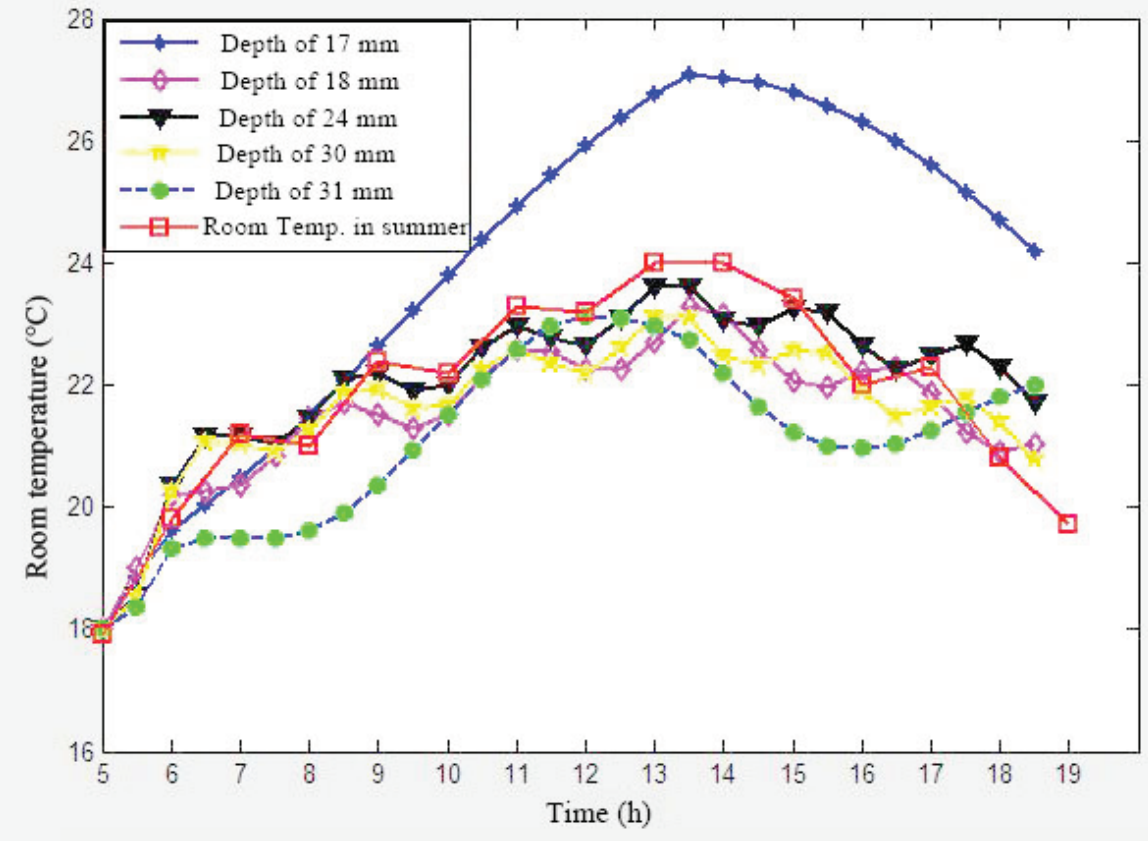

Figure 3. Comparison of temperatures calculated by the model with annual temperatures in summer 


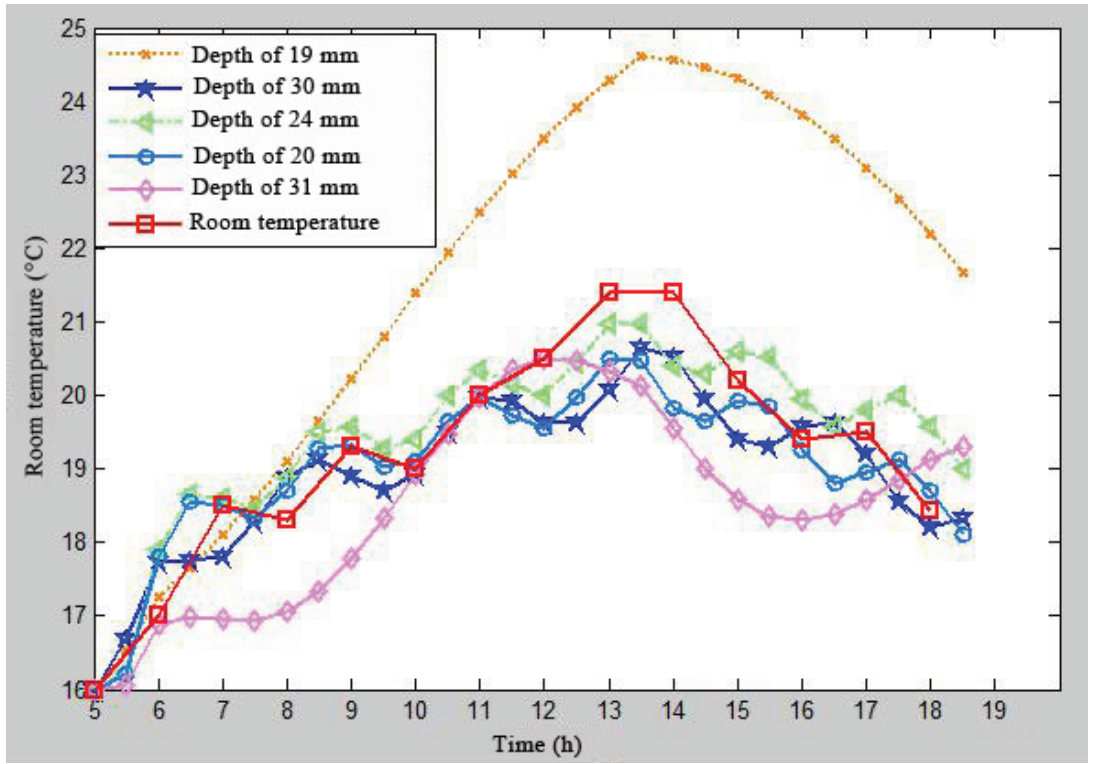

Figure 4. Comparison of temperatures calculated by the model with annual temperatures in winter

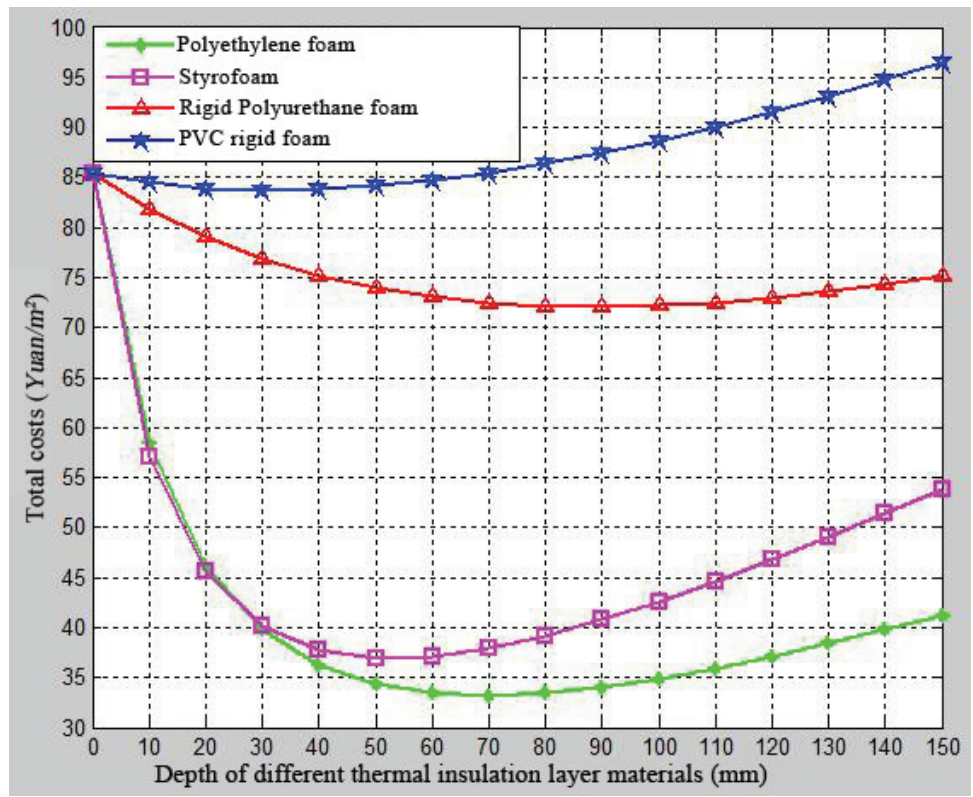

Figure 5. Relationship between depth of different thermal insulation layer materials and total costs 


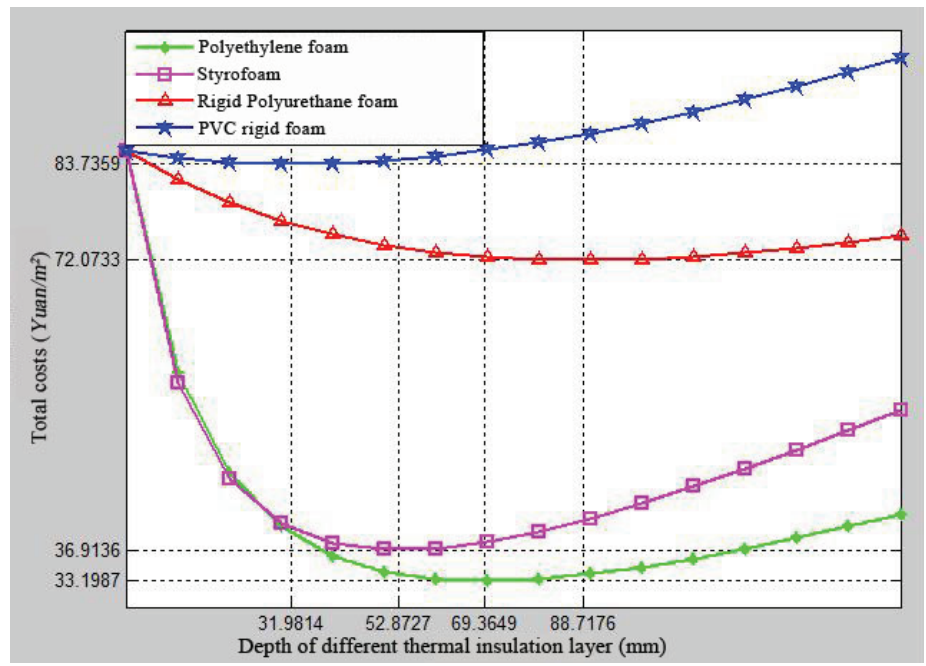

Figure 6. The corresponding depth of thermal insulation layer with the lowest costs

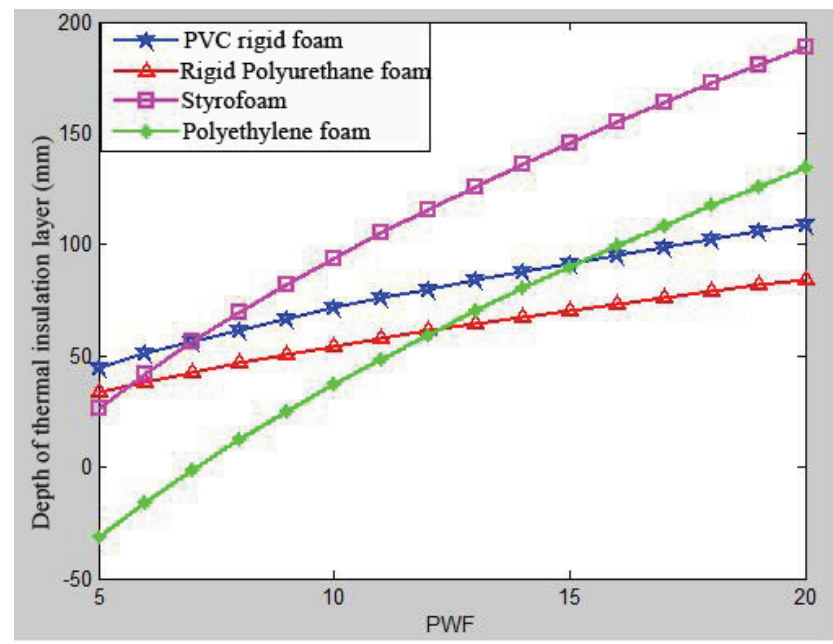

Figure 7. Relationship between depth of thermal insulation layer and PWF 


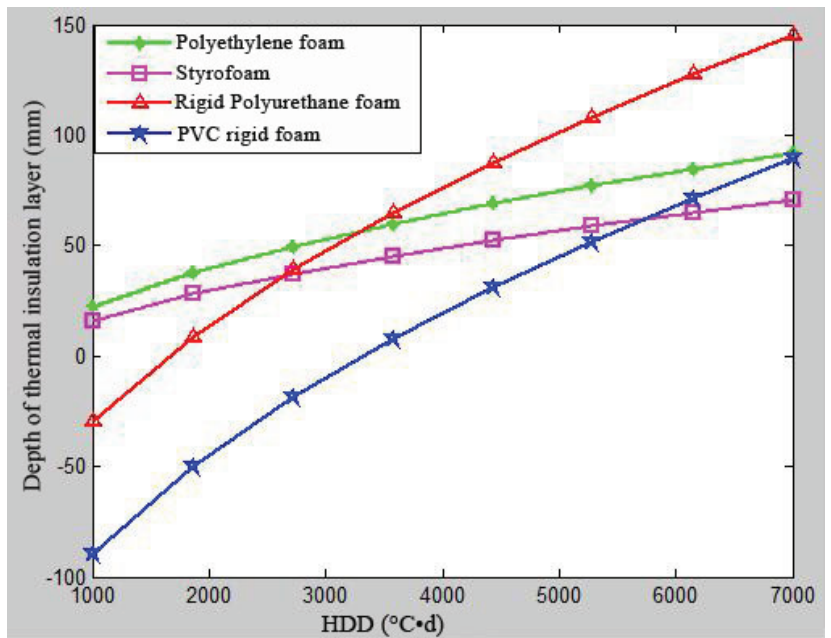

Figure 8. Relationship between depth of thermal insulation layer and HDD

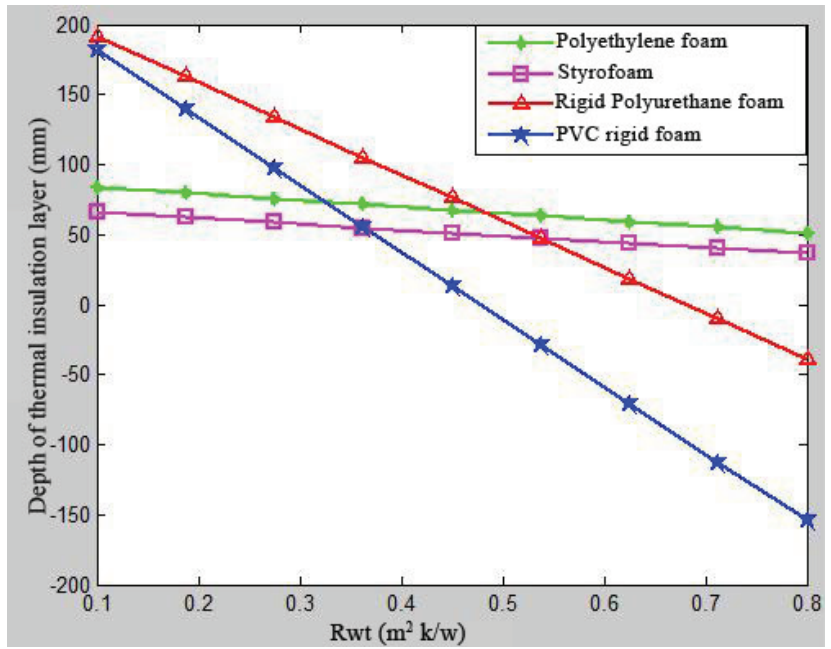

Figure 9. Relationship between depth of thermal insulation layer and $\mathrm{R}_{w t}$ 